\title{
The impact of the Iran Health System Reform Plan on the psychological empowerment of clinical faculty members
}

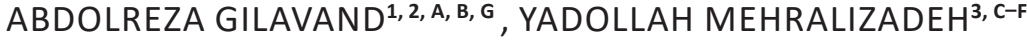 \\ ORCID ID: 0000-0003-4340-1843 ORCID ID: 0000-0002-0451-2455 \\ ${ }^{1}$ Department of Community Medicine, School of Medicine, Ahvaz Jundishapur University of Medical Sciences, \\ Ahvaz, Iran \\ ${ }^{2}$ Social Determinants of Health Research Center, Ahvaz Jundishapur University of Medical Sciences, Ahvaz, Iran \\ ${ }^{3}$ Department of Educational Administration, Faculty of Education and Psychology, Shahid Chamran University \\ of Ahvaz, Ahvaz, Iran
}

A - Study Design, B - Data Collection, C - Statistical Analysis, D - Data Interpretation, E - Manuscript Preparation, F - Literature Search, G - Funds Collection

Summary Background. Clinical faculty members are at the forefront of providing medical services in the Iran health system reform plan. Objectives. This study was conducted to investigate the impact of the Iran health system reform plan on the psychological empowerment of clinical faculty members.

Material and methods. The statistical population of this descriptive study included all clinical faculty members, with 90 members eventually participating in this study. To collect data, a researcher-made questionnaire, modelled on the PEQ standard, was used. Descriptive and inferential statistics were used to analyze the data through SPSS version 22 software.

Results. The dimensions of self-determination $(6.1 \pm 3.79)$, sense of competence $(5.9 \pm 3.91)$, impact $(5.7 \pm 3.76)$ and meaning $(5.2 \pm$ $3.45)$, respectively, obtained the highest scores. Hence, it can be concluded that the Iran health system reform plan has played a small role in the psychological empowerment of clinical faculty members. Variables such as gender, age, education, employment history and academic status of faculty members did not have a significant effect on their empowerment $(p<0.05)$. However, the location (hospital type) where services are provided $(p=0.039)$ and the full-time work of faculty members $(p=0.03)$ had a significant effect on their empowerment score.

Discussion and conclusions. Given the key role of clinical faculty members in the Iran health system reform plan and given the high importance of empowerment of staff to enhance their job satisfaction and improve organizational productivity, it is necessary to periodically monitor and evaluate this plan to enhance and eliminate its possible shortcomings. In this regard, providing sustainable and receivable financial resources for its continuation and elimination of injustice in payments to staff should be prioritized. Key words: health care reform, Iran, faculty, educational personnel, empowerment.

Gilavand A, Mehralizadeh Y. The impact of the Iran Health System Reform Plan on the psychological empowerment of clinical faculty members. Fam Med Prim Care Rev 2021; 23(4): 417-421, doi: https://doi.org/10.5114/fmpcr.2021.110354.

\section{Background}

Empowerment is one of the most effective ways to improve staff productivity and make the best use of their capacities and capabilities in line with organizational goals [1]. Empowerment has been considered from different perspectives. One of the most important of these perspectives is psychological empowerment. Psychological empowerment is defined as intrinsic job motivation, which includes the four dimensions of meaning, impact, sense of confidence and self-determination $[1,2]$. Studies conducted in Iran have shown that among some variables, such as transformational leadership [3], new information technologies [4], job enthusiasm and entrepreneurship [5], genuine leadership [6], organizational citizenship behavior [6], creativity [7], reducing job stress [8], job satisfaction [9], management strategies and resources of individual self-efficacy [10], emotional intelligence [11] and knowledge management [12] have a positive and significant relationship with psychological empowerment. The results of a study conducted by Mehrabian et al. in Iran under the title of "Identifying the factors affecting human productivity from the perspective of clinical and non-clinical faculty members" showed that psychological empowerment is the most important component for improving human productivity [13]. Sadri et al. reported that availability of resources and facilities [related to education and research] at the workplace was the most important factor influencing the psychological empowerment of the dental faculty members of the Islamic Azad University of Iran [14]. Investigating the factors related to psychological empowerment, the faculty members of the Tarbiat Moallem University of Tehran showed that the faculty members of this university had higher empowerment in the meaning dimension compared to other dimensions of empowerment, and the confidence dimension was at the lowest level [15]. The study conducted by Luna and Cullen at the University of Washington showed that the empowerment of faculty members had a direct relationship with annual evaluation, and faculty members who were evaluated showed a higher willingness for personal and specialized empowerment [16]. In Iran, the provision of medical and health services has undergone many changes over the last four decades; one of the most important of which was the integration of medical education in health services in 1985. As a result of these changes, these services are provided simultaneously by the universities of medical sciences affiliated with the Ministry of Health and Medical Education of Iran $[17,18]$. One of the other important changes that has also been made in recent years is the implementation of the health system reform plan. The health system reform plan has been implemented since May 2014, with the two main goals of increasing access and increasing justice in providing goods 
and providing health and medical services in all hospitals and healthcare centers affiliated with the Iran University of Medical Sciences. With the implementation of this plan, in addition to the financial support of people concerning health costs, the improvement of the quality of medical services in the inpatient wards of public hospitals was also considered. The goals of this plan have continued in four phases of "improving access, affordability and quality of treatment", "developing self-care", "balancing health care tariffs" and "transformation in medical education". Although this plan has been implemented for six years, some experts have reported an increase in induced demand, an increase in total medical costs, an increase in the number of referrals to public healthcare centers and an increase in the share of health expenditure in the household basket, as well as an increase in staff dissatisfaction due to injustice in payments and increased disruptions in drug supply chains as negative impacts of the plan. In addition, a lack of feasibility studies, a lack of sustainable resources to continue this plan, its inconsistency with some of Iran's upstream policies, the conflict of interest in policy-making, the priority of treatment over prevention, inefficient human resource management and the low effectiveness of policies have been reported as major challenges of this plan [19-21]. In a review study, Mehralizadeh et al. showed that the health system reform plan could successfully achieve its first and most important goals of supporting people financially concerning health costs and improving the quality of health services in inpatient wards of public hospitals [19]. However, some other studies have shown that due to some deficiencies, medical staff are not satisfied with the implementation of the health system reform plan in Iran $[21,22]$. Due to the high importance of staff empowerment in increasing organizational productivity and staff job satisfaction, researchers are always trying to evaluate, and thus improve, the empowerment of their staff [13]. Improving the performance of universities depends on many variables, among which qualified and empowered faculty members have a special status, and the empowerment of clinical faculty members of medical universities affiliated with the Ministry of Health and Education plays a key role in the optimal implementation of the health system reform plan. Increasing pressure on providing educational and health services by clinical faculty members, increasing the complexity of medical sciences and the emergence of new approaches to teaching and research and lack of time for clinical faculty members to fulfill different duties have made it necessary to empower faculty members in a variety of areas to take on different roles using different strategies.

\section{Objectives}

The present study was conducted to investigate the impact of the Iran health system reform plan (which is one of Iran's major and costly plans in recent years) on the psychological empowerment of clinical faculty members.

\section{Material and methods}

The Ahvaz Jundishapur University of Medical Sciences is one of the Type 1 universities of the Ministry of Health and Medical Education of Iran, which has 660 faculty members and more than 7,000 students at present. About half of the university faculty members are working at the medical school of this university, and two-thirds of them are clinical faculty members, and another one third of them are basic science faculty members. The present study is a descriptive and cross-sectional study that was conducted in the academic year of 2018-2019. Its statistical population included all clinical faculty members working at the Ahvaz Jundishapur University of Medical Sciences. 90 faculty members working at all teaching hospitals affiliated with this university having at least one year of employment history and a specialty and assistant professor academic degree were randomly included in the study. After explaining the objectives of the research and obtaining written consent by the samples, they were assured that their information would remain confidential, and they could leave the study at any time if they did not wish to cooperate. The questionnaires were distributed in four work shifts and at the workplace of the faculty members in four teaching hospitals of the university. Finally, among all distributed questionnaires, the data of 90 completed questionnaires was collected after excluding incomplete or non-returned questionnaires. The method of data collection was a questionnaire. The questionnaire used consisted of two sections, including demographic characteristics of people such as: age, gender, level of education, type of employment, employment history, academic degree, location of employment and type of service (full-time and part-time), and a researcher-made questionnaire was developed modeled on the Spreitzer Psychological Empowerment Questionnaire (PEQ). The questionnaire consists of 12 items [2] that measure and evaluate four dimensions of psychological empowerment from Spreitzer's point of view. These dimensions are meaning ( 3 items) - or consistency between work requirements and beliefs, values and behavior; sense of competence ( 3 items) - a personal belief that one feels he or she is successfully performing the assigned duties; self-determination ( 3 items) - a sense of right to choose or autonomy or freedom of action and independence in determining the activities necessary to perform job duties; and impact ( 3 items) - indicating the degree to which a person can influence the strategic, administrative and operational results of a job. These questions are scored on a 5-point Likert scale (including "I strongly disagree" with a score of 1 , "I disagree" with a score of 2, "I have no idea" with a score of 3, "I agree" with a score of 4, and "I strongly disagree" with a score of 5). It is evaluated based on the division of the lower bound (3-7), moderate bound (7-11) and the upper bound (11-15). The "Health System Reform Plan" option was also added to the content of the questionnaire. The validity of this questionnaire was evaluated and confirmed by using the opinions of clinical faculty members, and its reliability was confirmed by using Cronbach's alpha method, which was obtained at $85 \%$. Descriptive statistics (mean, standard deviation, percentage) and inferential statistics (independent $t$-Test and analysis of variance) and SPSS version 22 software were used for data analysis.

\section{Ethical approval and consent to participate}

Full ethical approval was obtained from the Ahvaz Jundishapur University of Medical Sciences under the number SDH-9706 and Ethics Code IR.AJUMS.REC.1397.370.

\section{Results}

A total of 90 clinical faculty members (faculty physicians) entered the study. According to the table, 72 people $(80 \%)$ were male, and 18 people (20\%) were female. Other individual characteristics of the statistical sample are presented in Table 1.

According to Table 2, the highest number of answers to the impact dimension was "I disagree" (47.2\%), the highest number of answers to the meaning dimension was "I disagree" (55.6\%), the highest number of answers to the sense of competence dimension was "I disagree" (46.4\%), and the highest number of answers to the self-determination dimension was "I disagree" (47.9\%).

According to Table 3, the mean score of the scope of self-determination (6.1 \pm 3.79$)$, sense of competence $(5.9 \pm 3.91)$, impact $(5.7 \pm 3.76)$ and meaning $(5.2 \pm 3.45)$ areas was at a low level.

According to Table 4, variables such as gender, age, education, employment history and academic degree of faculty members did not have a significant effect on their empowerment ( $p$ $>0.05)$. However, service location (hospital) $(p=0.039)$ and full-time work of faculty members $(p=0.03)$ had a significant effect on their empowerment score, and the full-time faculty members and faculty members of some hospitals had higher empowerment compared to faculty members of other hospitals. 


\begin{tabular}{|c|c|c|c|}
\hline \multicolumn{2}{|l|}{ Variables } & \multirow{2}{*}{$\begin{array}{l}n \\
72\end{array}$} & \multirow{2}{*}{$\frac{\%}{80}$} \\
\hline Gender & male & & \\
\hline & female & 18 & 20 \\
\hline \multirow[t]{3}{*}{ Age } & under 40 years & 36 & 40 \\
\hline & $40-50$ years & 30 & 33.3 \\
\hline & over 50 years & 24 & 26.7 \\
\hline \multirow[t]{3}{*}{ Education } & specialty & 24 & 26.7 \\
\hline & fellowship & 14 & 15.5 \\
\hline & sub-specialty & 52 & 57.8 \\
\hline \multirow[t]{2}{*}{ Employment history } & under 10 years & 48 & 53.3 \\
\hline & over 10 years & 42 & 46.7 \\
\hline \multirow[t]{3}{*}{ Academic degree } & assistant professor & 65 & 72.2 \\
\hline & associate professor & 16 & 17.8 \\
\hline & professor & 9 & 10 \\
\hline \multirow[t]{3}{*}{ Type of employment } & permanent & 36 & 40 \\
\hline & temporary-to-permanent & 36 & 40 \\
\hline & service commitment & 18 & 20 \\
\hline \multirow[t]{4}{*}{ Location (hospital) } & Imam Khomeini & 33 & 36.7 \\
\hline & Abuzar & 12 & 13.3 \\
\hline & Razi & 15 & 16.7 \\
\hline & Golestan & 30 & 33.3 \\
\hline \multirow[t]{2}{*}{ Full-time } & yes & 45 & 50 \\
\hline & no & 45 & 50 \\
\hline
\end{tabular}

\begin{tabular}{|l|l|l|l|l|}
\hline Table 2. Frequency of answers given to the four components of empowerment \\
\hline \multirow{2}{*}{ Answer } & Impact & Meaning & Sense of competence & Self-determination \\
\cline { 2 - 5 } & $n(\%)$ & $n(\%)$ & $n(\%)$ & $n(\%)$ \\
\hline Strongly agree & $(0) 0$ & $(0) 0$ & $(0) 0$ & $3(1.4)$ \\
\hline Agree & $(16.7) 51$ & $(11.1) 24$ & $(21.7) 45$ & $36(16.9)$ \\
\hline No idea & $(19.4) 57$ & $(13.9) 30$ & $(21.7) 45$ & $57(26.8)$ \\
\hline Disagree & $(47.2) 141$ & $(55.6) 120$ & $(46.4) 96$ & $102(47.91)$ \\
\hline Strongly disagree & $(16.7) 51$ & $(19.4) 42$ & $(10.1) 21$ & $15(7)$ \\
\hline Total & $(100) 300$ & $(100) 216$ & $(100) 207$ & $212(100)$ \\
\hline
\end{tabular}

\begin{tabular}{|l|l|l|l|l|}
\hline \multicolumn{5}{|l|}{ Table 3. Mean and standard deviation of the score of empowerment components } \\
\hline Area (range of score variations) & Mean & SD & Min & Max \\
\hline Impact (3-15) & 5.7 & 3.76 & 0 & 12 \\
\hline Meaning (3-15) & 5.2 & 3.45 & 0 & 12 \\
\hline Sense of competence (3-15) & 5.9 & 3.91 & 0 & 12 \\
\hline Self-determination (3-15) & 6.1 & 3.79 & 0 & 12 \\
\hline
\end{tabular}

\begin{tabular}{|c|c|c|c|c|c|}
\hline \multicolumn{2}{|l|}{ Variable } & \multirow{2}{*}{$\begin{array}{l}\text { Mean } \\
20.5 \\
29.4 \\
\end{array}$} & \multirow{2}{*}{$\begin{array}{l}\text { SD } \\
14.10 \\
10.71 \\
\end{array}$} & \multirow{2}{*}{\begin{tabular}{|l|} 
Test \\
Mann-Whitney
\end{tabular}} & \multirow{2}{*}{$\frac{p}{0.245}$} \\
\hline Gender & $\begin{array}{l}\text { male } \\
\text { female }\end{array}$ & & & & \\
\hline Age & $\begin{array}{l}\text { under } 40 \text { years } \\
40-50 \text { years } \\
\text { over } 50 \text { years }\end{array}$ & $\begin{array}{l}24.4 \\
22.2 \\
21.2 \\
\end{array}$ & $\begin{array}{l}11.24 \\
14.06 \\
19.78 \\
\end{array}$ & Kruskal-Wallis & 0.884 \\
\hline \multirow[t]{2}{*}{ Employment history } & less than 10 years & 23.1 & 14.49 & \multirow[t]{2}{*}{ Mann-Whitney } & \multirow[t]{2}{*}{0.597} \\
\hline & over 10 years & 20.6 & 13.43 & & \\
\hline \multirow[t]{2}{*}{ Education } & specialty & 23 & 16.07 & \multirow[t]{2}{*}{ Mann-Whitney } & \multirow[t]{2}{*}{0.895} \\
\hline & $\begin{array}{l}\text { fellowship } \\
\text { sub-specialty }\end{array}$ & $\begin{array}{l}19.2 \\
22.2\end{array}$ & $\begin{array}{l}11.03 \\
14.66\end{array}$ & & \\
\hline \multirow[t]{2}{*}{ Full-time } & yes & 16.5 & 12.22 & \multirow[t]{2}{*}{ Mann-Whitney } & \multirow[t]{2}{*}{0.03} \\
\hline & no & 29.2 & 13.78 & & \\
\hline
\end{tabular}




\begin{tabular}{|c|c|c|c|c|c|}
\hline \multicolumn{2}{|l|}{ Variable } & \multirow{2}{*}{$\begin{array}{l}\text { Mean } \\
20.5 \\
\end{array}$} & \multirow{2}{*}{$\begin{array}{l}\text { SD } \\
11.52 \\
\end{array}$} & \multirow{4}{*}{$\begin{array}{l}\text { Test } \\
\text { Kruskal-Wallis }\end{array}$} & \multirow{4}{*}{$\frac{p}{0.169}$} \\
\hline \multirow[t]{3}{*}{ Academic degree } & assistant professor & & & & \\
\hline & associate professor & 23.2 & 23.78 & & \\
\hline & professor & 38 & 10.82 & & \\
\hline \multirow[t]{4}{*}{ Hospital } & Imam Khomeini & 27.8 & 8.24 & \multirow[t]{4}{*}{ Kruskal-Wallis } & \multirow[t]{4}{*}{0.039} \\
\hline & Abuzar & 18.7 & 12.84 & & \\
\hline & Razi & 13.6 & 12.46 & & \\
\hline & Golestan & 13.4 & 12.79 & & \\
\hline
\end{tabular}

\section{Discussion}

The results of this study revealed that the clinical faculty members had the highest score among the four dimensions of psychological empowerment, including self-determination, sense of competence, impact and meaning, which, according to the manner of calculation using the Spreitzer Psychological Empowerment Questionnaire, can be concluded that the health system reform plan has played a small role in the psychological empowerment of clinical faculty members. In his study entitled "Investigating the relationship between empowerment and the perception of empowerment of staff at the teaching hospitals of Kerman in the center of Iran", Tourani et al. reported that staff had poor psychological empowerment [23]. The results of a study conducted by Gilavand et al. at the Dezful University of Medical Sciences in southwestern Iran also showed that the psychological empowerment of faculty members was relatively "low" [24]. Their results are consistent with those of our research. Gilavand and Hosseinpour also showed in another study that the psychological empowerment of nurses working in the teaching hospitals of the Ahvaz Jundishapur University of Medical Sciences in southwestern Iran was at a high level [25], which are inconsistent with results of our research. In a meta-analysis review study, Royan et al. also evaluated the psychological empowerment of nurses working in Iranian hospitals and reported their psychological empowerment at a moderate level [1].

The Iran health system reform plan, despite all the benefits, especially for patients and clients of health services, suffers some shortcomings which have caused dissatisfaction, especially among healthcare providers [19]. In the financial dimension, injustice in payments and lack of sustainable resources to continue this plan can also be considered as the main challenges of this project, which can increase the dissatisfaction of medical staff $[21,22]$. A study conducted by Heydarzadeh et al. at the Rafsanjan University of Medical Sciences in central Iran showed that most physicians were dissatisfied with the implementation of the health system reform plan and that the greatest dissatisfaction was related to ways of paying the wages and fees [26]. Ghorbani et al. also showed that the most dissatisfying factor for the staff of the Qazvin University of Medical Sciences was the way of paying the wages and fees after the implementation of the health system reform plan [27]. Bahmanziari et al. also showed that only $56 \%$ of the physicians of a teaching hospital of the Shiraz University of Medical Sciences in the center of Iran were satisfied with the health system reform plan [28]. In a review study conducted in 2017, Gilavand found that most nurses working at Iranian medical universities were dissatisfied with this plan [21]. This study also revealed that the type of service (full-time and part-time) of clinical faculty members had a significant effect on their psychological empowerment score, and some full-time faculty members had higher empowerment compared to part-time faculty members. The health system re- form plan has had a greater impact on the psychological empowerment of full-time faculty members, which is consistent with the results of a study conducted by Yousefi and Taziki [29].

\section{Conclusions}

Due to the fact that the medical education system and the healthcare system in Iran have been merged in the last 34 years, and these services are provided simultaneously by the universities of medical sciences affiliated with the Ministry of Health and Medical Education of Iran, attracting and retaining a skilled and experienced work force is one of the important priorities of these universities. Before implementing the health system reform plan, most clinical professionals preferred to work privately, in private offices and private hospitals, after graduation to earn higher wages. Thus, one of the important goals of the health system reform plan of Iran was to reduce the difference between the wages and fees of staff in public and private sector centers and hospitals to attract a skilled work force in the health and treatment areas in university hospitals. However, a lack of sustainable and achievable financial resources and injustice in paying wages for staff have made it difficult to continue this plan. One of the important issues in financing the world's health systems is the issue of the sustainability of the financial resources of these health systems. For example, if a greater number of resources are injected into a country's treatment system at a certain period of time, it will increase demand and increase the level of price according to an economic principle. Hence, if resources of this field decrease for any reason or do not increase proportionally in such situations, this will lead to severe inflation, followed by a recession in the health market. In such a situation, irreparable damage will be imposed on the health system in the short term, and this will cause a kind of disruption in the healthcare market, which will increase the expectations of service providers, and conditions will be provided for create problems such as imbalances in the benefits and salaries of health care workers. Thus, one of the most important challenges of the Iran health system reform plan at present is the lack of sustainable and achievable financial resources and injustice in payments to staff. One of the cases proposed for the sustainability of the resources in the health system reform plan so far is the plan of allocating one percent of value-added tax (VAT) on harmful goods (such as carbonated beverages, cigarettes, etc.). Thus, due to the key role of clinical faculty members in the Iran health system reform plan and given the high importance of empowering staff to enhance their job satisfaction and improve organizational productivity, it is necessary to periodically monitor and evaluate this plan. Its possible shortcomings must also be resolved, especially the provision of sustainable and receivable financial resources to continue the plan, and elimination of injustice in the payment to staff should be prioritized. 


\section{References}

1. Royan S, Alikhani M, Mohseni M, et al. Nurses' psychological empowerment in Iran: a systematic review and meta-analysis. Ann Trop Med Public Health 2017; 10(61): 1558-1562, doi: 10.4103/ATMPH.ATMPH_509_17.

2. Spreitzer GM. Social structural characteristics of psychological empowerment. Academy of Management Journal 1996; 39: 483-504, doi.org/10.5465/256789.

3. Bakhshandeh G, Abbaspour J, Chitsaz A. Meta-analysis of the influence of transformational leadership on employees' psychological empowerment in Iran. Transformation Management 2019; 8(15): 45-66, doi: org/10.22067/pmt.v8i15.43455.

4. Dehghani Soltani M, Mesbahi M, Avami M, et al. Effect of using new information technologies on psychological empowerment of employees by explaining the role of mediator of knowledge sharing (case study: Imam Khomeini Naval Academy's staff). Teaching in Marine Sciences 2018; 5(1): 41-59.

5. Khaleghkhah A, Nemati V, Ebrahimi S, et al. The relationship between psychological empowerment and career enthusiasm in predicting entrepreneurship from staff viewpoint in Shahid Beheshti University of Medical Sciences. Journal of Health and Hygiene 2018; 9(4): 432-441.

6. Goudarzvand Chegini M, Abdolahzadeh Lalehdashti M, Rezaee Kelidbari HR. Relationship between authentic leadership, psychological empowerment and positive job behaviors in emergency department staff. Jour Guilan Uni Med Sci 2018; 27(107): 61-68.

7. Ghiasi Nadishan S, Jahani Javanmardi F, Khorsandi Taskoh A. The relationship between psychological empowerment and creativity among the staff of the Ministry of Communications and Information Technology. Innovation \& Creativity in Human Science 2017; 6(3): 77-96.

8. Pouraboli B, Esfandiari S, Ramezani T, et al. Effectiveness of their teaching skills to reduce stress job psychological empowerment of nursing staff in intensive care units in the center of Shiraz Shahid Rajaee 1392. J Clin Nurs Midwife 2016; 5(1): 23-35.

9. Bonyad Karizme T, Rahimi Pordanjani T, Mohamadzadeh Ebrahimi A. The relationships between structural and psychological empowerment and job satisfaction among nurses. HAYAT 2016; 22(3): 201-215.

10. Rezaeemanesh B, Barani S. Effective factors of human resources psychological empowerment. JMDP 2014; 26(4): 101-118.

11. Mehrabian F, Ahmadinezhad M, Taheri M. The relationship between emotional intelligence and empowerment of staff in Guilan Health Centers. RME 2016; 8(3): 45-52.

12. Galavandi $\mathrm{H}$, Ashrafisalimkandi F. Investigate the relationship between knowledge management and empowerment among the staff of Urmia University. Journal of Modern Thoughts in Education 2017; 12(2): 123-137.

13. Mehrabian F, Nasirpour AA, Keshavars Mohamadian S. Factors affecting human resources productivity in Guilan University of Medical Sciences using path analysis. J Adv Med Biomed Res 2011; 19(75): 94-106.

14. Sadri D, Jahanbani J, Fayazi M, et al. Evaluation of views of faculty members on effective strategies of empowerment and related factors in the Dental Branch of Islamic Azad University in 2014. J Res Dent Sci 2016; 12(4): 193-201.

15. Abdolahi B, Heidari S. Avamele mortabet ba tavanmandsaziye aezaye hayate elmiye daneshgah: motaleye mowrediye daneshgahe tarbeyet moaleme tehran. Amouzeshe Aliye Iran 2009; 5: 112-135.

16. Luna G, Cullen DL. Improwing the faculty mentoring Redirected and Renewed. Washington: The George Washington University Press; 1995.

17. Majdzadeh R, Nedjat S, Denis JL, et al. Linking research to action in Iran: two decades after integration of the Health Ministry and the medical universities. Public Health J 2010; 124(7): 404-411.

18. Gilavand A, Mehralizadeh $\mathrm{Y}$, Hosseinpour M, et al. A review on pathology of the integration of medical education system with Health Services at Iran's Ministry of Health and Medical Education. Future Med Educ J 2018; 8(3): 47-56, doi: 10.22038/fmej.2018.33896.1218.

19. Mehralizadeh Y, Gilavand A, Sheykhi Alizadeh M, et al. Evaluation of the Health System Reform Plan in Iranian universities of medical sciences in terms of community empowerment: a review. If there are images in this attachment, they will not be displayed. Download the original attachment. IAJPS 2017; 4(12): 4566-4579, doi.org/10.5281/zenodo.1119231.

20. Doshmangir L, Moshiri E, Mostafavi H, et al. Policy analysis of the Iranian Health Transformation Plan in primary healthcare. BMC Health Serv Res 2019; 19, doi.org/10.1186/s12913-019-4505-3.

21. Gilavand A. Studying nurses' satisfaction with the Health System Development Plan at Iranian Universities of Medical Sciences: a review. IAJPS 2018; 5(3): 1404-1408, doi: 10.5281/zenodo.1197500.

22. Gilavand A, Mehralizadeh Y. Evaluation of clinical faculty members' satisfaction with implementation of Health System Reform Plan in Iran: a study at the Ahvaz Jundishapur University of Medical Sciences. Future Med Educ J 2020; 10(2): 3-8, doi: 10.22038/ fmej.2020.45074.1304.

23. Tourani T, Yazdi Feizabadi V, Gohari MR. A study on empowerment atmosphere in relation with empowerment perception on Kerman teaching hospital s personals. Journal of Health Administration 2008; 11(31): 17-26.

24. Gilavand A, Mohammadbidaghi M, Moosavi A. Studying the psychological empowerment of faculty members of Dezful University of Medical Sciences in Southwestern Iran. J Res Med Dent Sci 2018; 6(6): 43-49.

25. Gilavand A, Hosseinpour P. Investigating the psychological empowerment of nurses in educational hospitals: a study in Ahvaz Jundishapur University of medical sciences in southwest Iran. J Res Med Dent Sci 2019; 7(2): 159-163.

26. Heidarzadeh A, Shamohammadipour P, Sadeghi T, et al. Healthcare workers' satisfaction with their working conditions after the implementation of the healthcare reform plan in Rafsanjan University of Medical Sciences, Iran, in 2015. JOHE 2015; 4(1): 43-49.

27. Ghorbani-Nia R, Khezri A, Kamali S, et al. Survey of nurses' satisfaction with the Healthcare Reform Plan at Pasteur Hospital of Bam, Iran, 2016. Health Inf Manage 2017; 14(3): 138-141.

28. Bahmanziari N, Bastani P, Moradi R, et al. Nurses' satisfaction of implementation of Health System Evolution Plan in Teaching Hospitals of Shiraz City, 2015 (IRAN). Qom Univ Med Sci J 2017; 11(8): 85-93.

29. Yousefi MR, Taziki MH. The approach of full-time faculty members in clinical practice: a qualitative study. Educ Strategy Med Sci 2018; 11(2): 115-122.

Tables: 4

Figures: 0

References: 29

Received: 07.06.2020

Reviewed: 23.06 .2020

Accepted: 01.09.2020
Address for correspondence:

Abdolreza Gilavand, PhD, Assistant Professor

Department of Community Medicine

School of Medicine

Ahvaz Jundishapur University of Medical Sciences

Ahvaz, Iran

Tel.: +989166423747

E-mail: gilavand_a@ajums.ac.ir, gilavanda@gmail.com 